\title{
Predict the Ultimate Moment Capacity of Reactive Powder Concrete Beams Exposed to Fire Flame Using Artificial Neural Network and Multiple Linear Regression Models
}

\author{
Prof.Dr. Mohammed Mansour Kadhum ${ }^{\# 1}$, Zaid Ahmed Mohammed ${ }^{\# 2}$ \\ ${ }^{\# 1,2}$ Department of Civil Engineering, College of Engineering, University of Babylon, Iraq. \\ ${ }^{1}$ E-mail of the corresponding author:drmohalkafaji@gmail.com \\ ${ }^{2}$ E-mail of the corresponding author:zaid971@gmail.com
}

\begin{abstract}
In this paper, the mathematical model has been used to predicting ultimate bending moment capacity of RPC and NSC beam specimens. From observed data and present experimental test results, Multi Linear Regression technique (RT) and Artificial Neural Network Multi Layers Perceptron (ANNMLP) models are proposed for predictions. The accuracy of the proposed equations was examined by comparison with similar existing equations and available experimental results. The models are built, trained and tested using 25 data sets. The data used in the models consists of four input parameters, which are the compressive strength $f_{c u}$, volume fraction of steel fibers $V_{f}$, concrete cover $C C$, burning temperature level $T_{L}$.A combined experimental and modeling study was taken to develop a database of the estimation ability of the effects of exposure to real fire flame on ultimate load capacity of RPC and NSC in addition to others (independent variables) to predict the dependent variable using IBM $^{\circledR}$ SPSS $^{\circledR}$ Statistics version 21 program. It is shown that ANN model with three neurons in hidden layer predicts the ultimate moment capacity $M_{u-A N N}$ of reinforced concrete beams before and after exposure to fire flame with high degree of accuracy, the moment capacities predicted by ANN $M_{u-A N N}$ are in line with the results provided by the ultimate moment capacity of experimental test $M_{u-t e s t}$.
\end{abstract}

Keywords - Reactive powder concrete beams, Fire flame, artificial neural networks, multiple linear regressions, ultimate moment capacity.

\section{INTRODUCTION}

Reactive powder concrete (RPC) is the generic name for a class of cementitious composite materials developed by the technical division of Bouygues, laboratory in France in the early 1990's. It is characterized by extremely good physical properties, particularly strength and ductility[1]. RPC is a relatively new cement-based material composed of cement, ultra-fine reactive powder, and high-quality fine aggregate. Through elimination of the coarse aggregates and reducing the water-tocementitious material ratio, RPC has the unique properties of ultra-high compressive strength and excellent durability [2]. RPC is a new generation concrete developed through microstructure enhancement techniques for cementitious materials. As compared to ordinary cementbased materials, the primary improvements of RPC include the particle size homogeneity, porosity, and microstructures [3]. Nowadays, RPC is regarded as a promising material for special pre-stressed and precast concrete members, including those industrial and nuclear waste storage facilities.

More and more attention has been paid on the mechanical properties of RPC at room temperature [3], [4], but few studies have been conducted on the residual mechanical properties of RPC after elevated temperatures [5], [6].

Most of the previous studies indicated two important components (as key components) for the successful performance of the concrete in fire; the first deals with its essential properties as a construction material, and the second one deals with its functionality in a structure. Concrete was known to be non-combustible with slow rate of heat transfer [7].

Many researchers studied the effect of fire on ordinary concrete, reinforced concrete members on exposing such members to high temperatures in special ovens or fire flame. They worked on the strength and deformation properties at elevated temperatures. However, no works were done on the structural behavior of reactive powder concrete (RPC) beam specimens exposed to direct fire flame. 


\section{Materials and Methods}

\section{EXPERIMENTAL DETAILS}

Effective production of concrete mix is achieved by more stringent requirements on materials selecting, controlling and proportioning the entire ingredient.

\section{Materials:}

The RPC considered here is prepared by the following ingredients:

ASTM Type I Portland cement produced in Iraq of (MASS) and taken from local markets, the used cement conforms to Iraqi standard [8]; natural sand $(0-600 \mu \mathrm{m}$ with a specific gravity of 2.7), the results show that the grading and sulfate content are conformed to the requirements of [9]; a polycarbokylate-based superplasticizer (SP),complies with [10]; Densified micro-silica fume from BASF, Silica fume is produced in conformance with the [11]specifications and brass-coated steel micro-fibers, with a density of $7860 \mathrm{~kg} / \mathrm{m}^{3}$, a length of $13 \mathrm{~mm}$, a diameter of $0.18 \mathrm{~mm}$ and an $1 / \mathrm{d}$ ratio of 72 . The cross section of the fiber was circular. The chemical composition and physical properties of cement and silica fume used are presented in Tables I and II respectively.

TABLE I. Chemical composition and physical properties of cement

\begin{tabular}{|c|l|l|l|l|l|l|l|l|l|l|}
\hline $\begin{array}{c}\text { Chemical } \\
\text { Composition }\end{array}$ & Composition & $\mathrm{CaO}$ & $\mathrm{SiO}_{2}$ & $\mathrm{Al}_{2} \mathrm{O}_{3}$ & $\mathrm{Fe}_{2} \mathrm{O}_{3}$ & $\mathrm{MgO}$ & $\mathrm{SO}_{3}$ & L.O.I. & I.R. & L.S.F. \\
\cline { 2 - 9 } & Content $\%$ & 61.56 & 21.32 & 5.33 & 3.41 & 2.96 & 2.43 & 1.57 & 0.76 & 0.87 \\
\hline $\begin{array}{c}\text { Physical } \\
\text { properties }\end{array}$ & \multicolumn{10}{|l|}{ Fineness (Blaine Method), $\mathrm{m}^{2} / \mathrm{kg}$} \\
\cline { 2 - 3 } & \multicolumn{1}{|l|}{ Compressive strength, $\mathrm{MPa}$ at 7 days } & & 320 \\
\hline
\end{tabular}

TABLE II. Chemical composition and physical properties of silica fume

\begin{tabular}{|l|l|c|}
\hline \multicolumn{3}{|c|}{ SPECIFICATIONS } \\
\hline \multicolumn{3}{|c|}{ Chemical Requirements } \\
\hline Oxide Composition & Content & ASTM C-1240 Limitations \\
\hline Silicon dioxide $\left(\mathrm{SiO}_{2}\right)$ & 93.47 & $\geq 85 \%$ \\
\hline Moisture content & 0.27 & $\leq 3 \%$ \\
\hline Loss on Ignition (L.O.I) & 3.82 & $\leq 6 \%$ \\
\hline \multicolumn{2}{|c|}{ Physical Requirements } \\
\hline Oversize percent retained on $45 \mu \mathrm{m}$ sieve, max, \% & 2.54 & $>10 \%$ \\
\hline $\begin{array}{l}\text { Accelerated strength activity index with Portland } \\
\text { cement 7 days, min. percent of control, \% }\end{array}$ & 126.07 & $\geq 15$ \\
\hline Specific surface, $\min ,\left(\mathrm{m}^{2} / \mathrm{g}\right)$ & 22.28 & \\
\hline
\end{tabular}

III. Concrete Mixing Procedure

The mixing procedure is an important thing to obtain the required workability and homogeneity. The RPC mix ratios are based on guidelines given in previous studies [12], [13]. The mixes are detailed in Table III.

TABLE III. Details of the mixes used in this research investigation

\begin{tabular}{|c|c|c|c|c|c|c|c|c|c|c|}
\hline \multirow[b]{2}{*}{$\begin{array}{l}\text { Concrete } \\
\text { Type }\end{array}$} & \multirow{2}{*}{$\begin{array}{c}\text { Nominal } \\
\text { Compressive } \\
\text { Strength } \\
\text { (MPa) }\end{array}$} & \multicolumn{9}{|c|}{ Mix Proportion } \\
\hline & & $\begin{array}{l}\text { Cement } \\
\mathrm{Kg} / \mathrm{m}^{3}\end{array}$ & $\begin{array}{l}\text { Sand } \\
\mathrm{Kg} / \mathrm{m}^{3}\end{array}$ & $\begin{array}{l}\text { Gravel } \\
\mathrm{Kg} / \mathrm{m}^{3}\end{array}$ & $\begin{array}{l}\text { Silica } \\
\text { fume } \\
\mathrm{Kg} / \mathbf{m}^{3}\end{array}$ & $\begin{array}{l}V_{f} \\
\%\end{array}$ & $\begin{array}{c}\text { Steel } \\
\text { Fiber } \\
\text { Kg/m } / \mathbf{m}^{3}\end{array}$ & $\begin{array}{l}\text { W/cm } \\
\text { Ratio }\end{array}$ & $\begin{array}{l}\text { Water } \\
\text { content } \\
\mathrm{Kg} / \mathrm{m}^{3}\end{array}$ & $\begin{array}{l}\text { S.P by } \\
\text { wt. of } \\
\text { cm\% }\end{array}$ \\
\hline RPC0 & 122 & 925 & 925 & - & 185 & 0.0 & 0.0 & 0.18 & 200 & 5 \\
\hline RPC1 & 133 & 925 & 925 & - & 185 & 1.0 & 78.5 & 0.18 & 200 & 5 \\
\hline RPC2 & 145 & 925 & 925 & - & 185 & 2.0 & 157 & 0.18 & 200 & 5 \\
\hline NSC & 49 & 550 & 715 & 825 & - & - & - & 0.40 & 220 & - \\
\hline
\end{tabular}




\section{DETAILS OF BEAMS}

Thirty beam specimens with $(100 \times 100 \times 1000 \mathrm{~mm})$ dimension. Each beam was reinforced with $4 \varnothing 8 \mathrm{~mm}$ as longitudinal reinforcement, and $\varnothing 6 \mathrm{~mm}$ bars were used for stirrups reinforcement at $100 \mathrm{~mm} \mathrm{C} / \mathrm{C}$ as shown in Fig.1. All the beams, are tested under flexural moment.

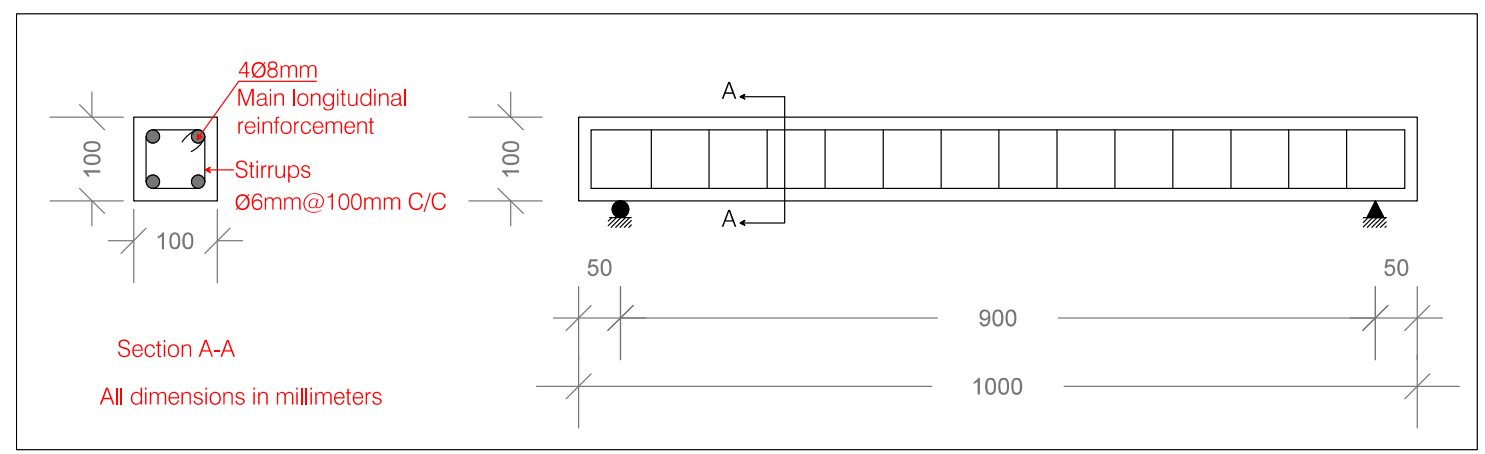

Fig. 1. Details of reinforced concrete beams

\section{LOAD MEASUREMENT}

The load is applied in two points loading with $300 \mathrm{~mm}$ spacing between these points as shown in Fig. 2, the test continues up to failure, using a hydraulic machine $150 \mathrm{KN}$ capacity. Before loading,

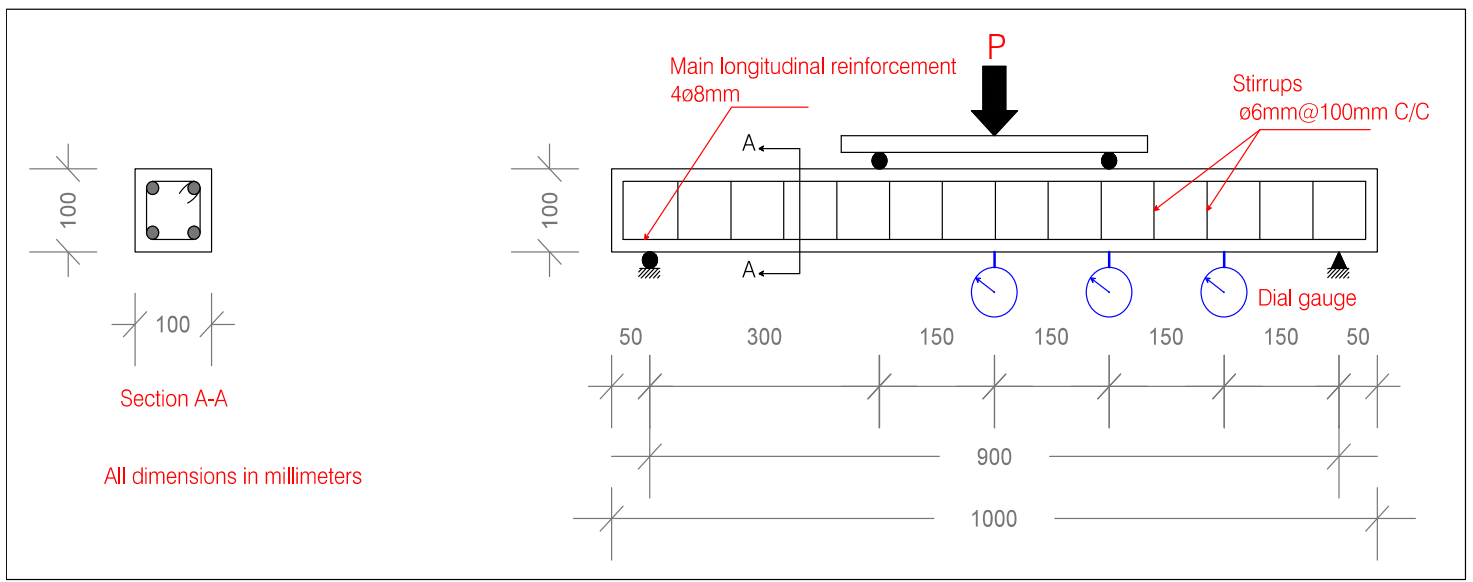

Fig. 2. Loading and test setup of beam specimens

\section{Burning Temperature ANd Testing Methodology}

After the curing procedure for the specimens, the burning procedure was applied. The specimens were burnt with direct fire flame at temperatures $\left(150,200,300\right.$ and $\left.400^{\circ} \mathrm{C}\right)$ with a net of methane burners inside a brick stove.

The following steps explained the burning procedure:

- Carrying concrete samples carefully into position by hand inside the stove to avoid unexpected external stresses.

- The concrete specimen fair-faced toward the fire flame exposure to be able to observation the concrete spalling and cracking clearly and test the specimen in the same direction.

- When the target temperature reached, two digital thermometers continuously measured the temperature; one of them was positioned in fire flame contact area, while the other was at the face of the specimen. Also three thermocouples were used to measure the temperature, two of them were positioned at $25 \mathrm{~mm}$ and mid depth $50 \mathrm{~mm}$ of the cross-section of reinforced NSC and RPC beams, another one was positioned at the longitudinal steel reinforcement layer of the beam, the holes made it during the concrete cast of specimen. The Fig. 3 depicts the burning process.

- In addition, the temperature of concrete and steel reinforcement was measured at different depths by applying infrared ray thermometer from about approximately 2 meters from the concrete exposed to fire.

- Test the concrete specimens after cooling to reach the room temperature around $25^{\circ} \mathrm{C}$.

- Finally test the beams with two point loads 
In this study for cooling regime, the fire flame was switched off at the end of the exposure time. The samples were removed immediately after being extinguished and picked by using thermal gloves. All samples were cooled by foam spray fire extinguisher before testing. This process of cooling adopted in this work in order to simulate this problem to practical site conditions. See Fig. 4.

These test methods technology met various standards such as [14]. In this research, the exposure time is one hour and the temperature levels are $150,200,300$ and $400{ }^{\circ} \mathrm{C}$.

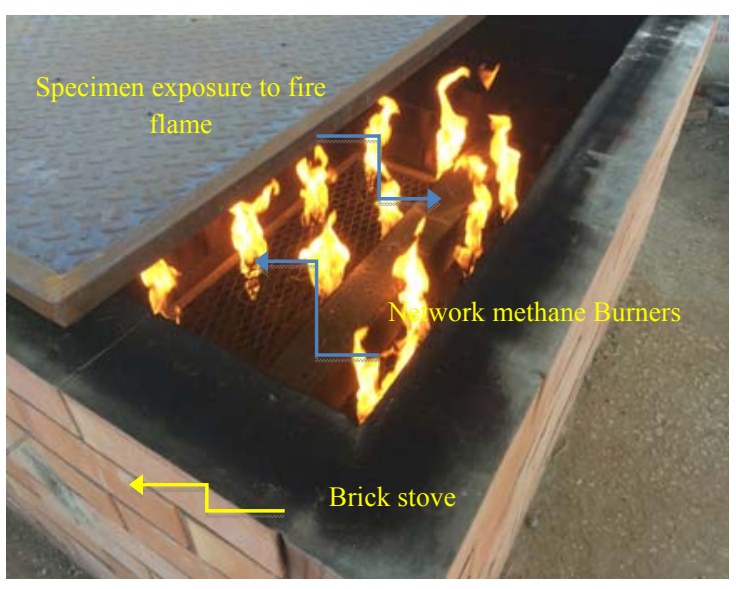

Fig. 3. Burning process for beam specimens.

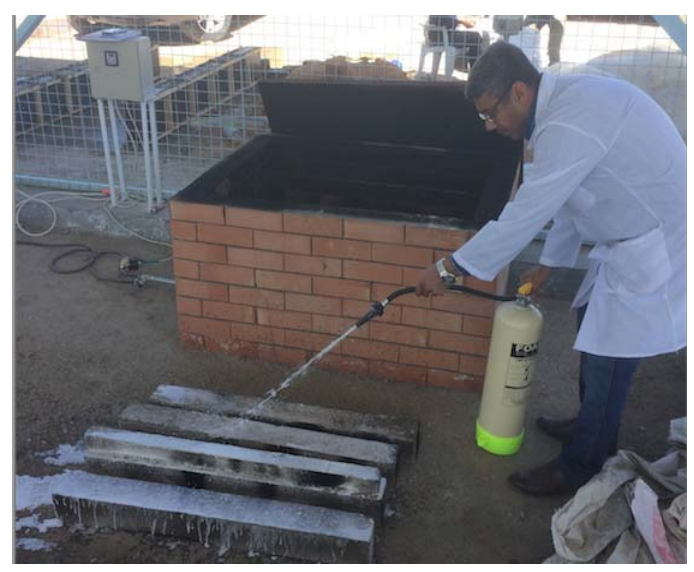

Fig. 4. Cooling by foam spray.

\section{RESULTS AND DISCUSSION}

\section{Residual First Crack Load and Ultimate Load of Beams Exposed to Fire}

It is very important for reinforced concrete beams as it makes concrete fail in flexure to prevent sudden collapse (yielding of steel reinforcement). According to experimental tests, it can clearly note that the values of ultimate load capacity decrease when the beams were exposed to burning temperature $\left(200,300\right.$ and $\left.400^{\circ} \mathrm{C}\right)$ for RPC and NSC reinforced beams, but the values of ultimate load capacity increase when the beams of RPC were exposed to burning temperature at $150^{\circ} \mathrm{C}$. The longitudinal reinforcement ratio may also have a significant effect on the first cracking load as well as on ultimate load, and the ratio of first cracking load to the ultimate load may decrease clearly with using longitudinal reinforcement ratio for RPC beam specimens before and after exposure to fire flame.

Two different concrete cover CC thickness used (15 and 30mm), and two percentages of micro steel fiber volume fraction used in this study $(1 \%$ and $2 \%)$. In general, the increase of micro steel fiber volume fraction increased the ultimate load carrying capacity and the first crack load of the beam specimens for the same concrete cover. Increasing the micro steel fiber from 1.0 to $2.0 \%$ increased the ultimate load carrying capacity by $(12.9,11.1,4.0,4.8$ and $19.0 \%)$ at burning temperatures $\left(150,200,300\right.$ and $\left.400^{\circ} \mathrm{C}\right)$ respectively as shown in Fig. 5, and the first crack load decreased by $(22.0,14.4,6.6$ and $8.1 \%)$ at $\left(25,150,200,300^{\circ} \mathrm{C}\right)$ respectively. This is normally explained by the efficiency of steel fibers in arresting the propagation and controlling the growth of the flexure and diagonal cracks within the beam when they cross them, and hence, steel fibers maintain the beam integrity throughout the post-cracking stages of behavior. The beam, hence could withstand greater loads and deflection before failure.

While for the same micro steel fiber volume fraction $V_{f}=2.0 \%$, decrease of concrete cover CC increased the ultimate load carrying capacity and the first crack load of the beam specimens. Decreasing the CC from 30 to 15 increased the ultimate load carrying capacity by $(12.0,14.4,14.5,12.1$ and $18.4 \%)$ at $(25,150,200,300$ and $\left.400^{\circ} \mathrm{C}\right)$ respectively, and the first crack load increased by $(15.1,13.4,16.9$ and $24.0 \%)$ at $\left(25,150,200,300^{\circ} \mathrm{C}\right)$ respectively as shown in Fig. 6. From this Figure, it can be noted that the concrete cover had insignificant effect on load carrying capacity of beam specimens for all burning temperatures.

Steel fiber volume fraction and longitudinal reinforcement ratio have positive effect on ultimate load. Ranging each of percentage of steel fibers between zero to $2.0 \%$ raises max failure load by $(24.8,25.8,25.7,27.1$ and $18 \%$ ) respectively.

To enhance the fire resistance of reinforced concrete members, the conventional design method in most publications including building Codes (ACI; BS;EuroCode; Joint, etc.), is to increase the concrete cover CC thickness of reinforced concrete members, as shown in Table IV. 
TABLE IV. Concrete cover thickness of reinforced concrete simply supported beams with dense concrete (Joint 1978)

\begin{tabular}{|c|l|l|l|l|}
\hline Duration of fire resistance (min) & 30 & 60 & 90 & 120 \\
\hline Minimum cover (mm) & 20 & 30 & 40 & 60 \\
\hline
\end{tabular}

From Table IV, it can be seen that the increase in the fire resistance of reinforced concrete members is proportional to the increase in the CC thickness.

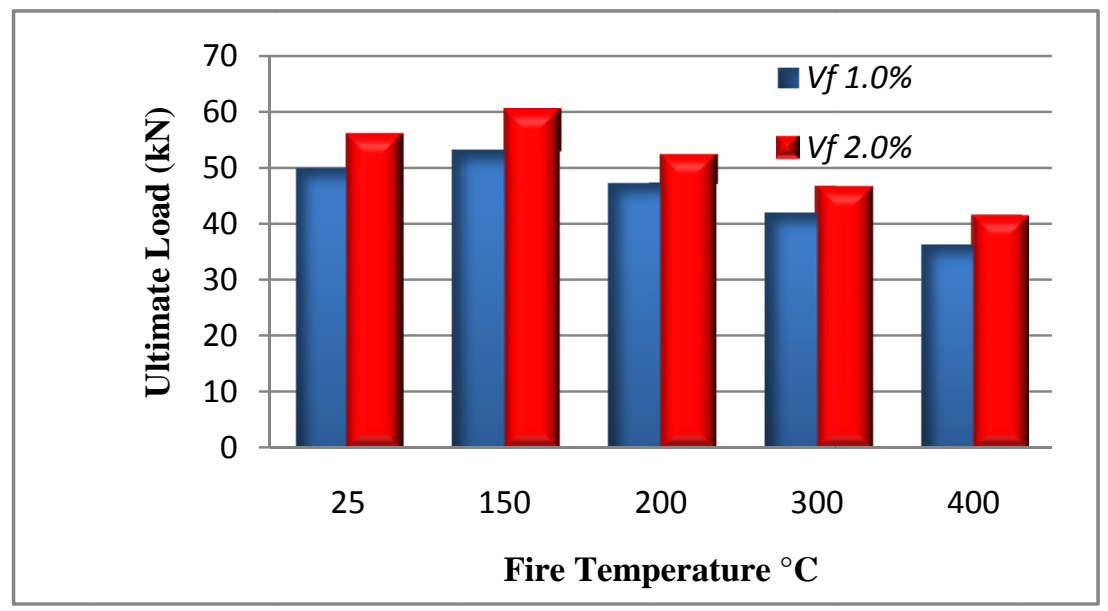

Fig. 5. Effect of steel fibers volumetric ratio on ultimate Load of RPC beam specimen for groups one for the same CC $15 \mathrm{~mm}$.

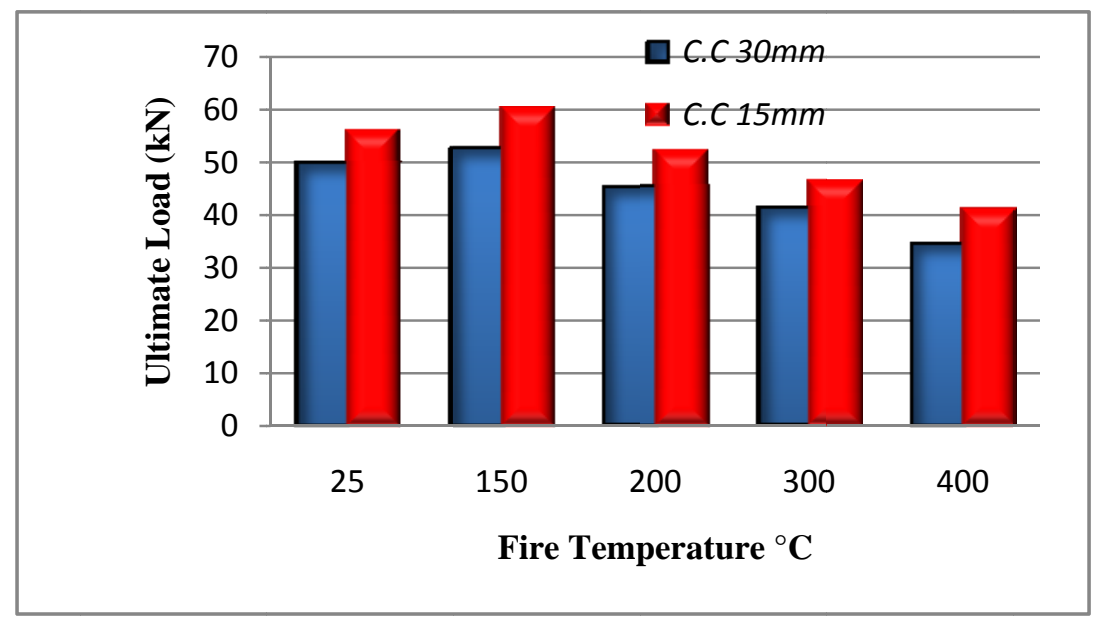

Fig. 6. Effect of concrete covers on ultimate Load of RPC beam specimen for groups one and three for the same steel fibers volumetric ratio.

\section{Artificial Neural Networks (ANNs)}

In recent decades, Artificial Neural Network (ANN) has been used to predict concrete properties. ANN is a powerful tool for system modeling in a wide range of applications. The mostimportantadvantageoftheANN model is that the priority of thefunctional relationship among the various variables is not required. The ANNs automatically builda relationship for network architecture as experimental data through alearning algorithm. Artificial neural network can be represented as a simplified model of the nervous system. It consists of highly interacted simple processing elements [15]. The elements are called artificial neurons or nodes.

\section{MUltiple Linear Regression Technique (RT)}

Multiple linear regression (multiple linear least squares fittings) attempts to model the relationship between two or more explanatory variables (independent variables) and a response variable (dependent variables) by fitting a linear equation to observed data. Every value of the independent variable $x$ is associated with a value of the dependent variable $y$. The mathematical equation for regression technique is given in Eq. (1):

$$
y=a+b_{1} x_{1}+b_{2} x_{2}+\ldots+b_{n} x_{n}+\varepsilon .
$$


The description of the parameters used:

$y$ : Response variable (dependent);

$x_{i}$ : Predictor variables (independent);

$b_{i}$ : Calculated coefficient parameters;

ع: Error term.

When selecting the model for the multiple linear regression analysis another important consideration is the model fit. Adding independent variables to a multiple linear regression model will always increase its statistical validity, because it will always explain a bit more variance (typically expressed as $\mathrm{R}^{2}$ ).

Multiple linear regression analysis consists of more than just fitting a linear line through a cloud of data points. It consists of three stages:

i. Analyzing the correlation and directionality of the data.

ii. Estimating the model, i.e., fitting the line.

iii. Evaluating the validity and usefulness of the model.

There are three major uses for Multiple Linear Regression Analysis: 1- causal analysis, 2- forecasting an effect and 3- trend forecasting. Other than correlation analysis, which focuses on the strength of therelationship between two or more variables, regression analysis assumes a dependence or causal relationship between one or more independent and one dependent variable.

Developing multiple linear regressions model to use in the prediction of RPC and NSC beams ultimate moment capacity. Regression models can be classified as linear and non-linear models. To make a good prediction with non-linear regressionmodels, you have to possess preliminary information on the assumed degree of the model, therefore, is preferred the use of the linear regression model. The prediction multiple linear regression model (variables and coefficients) used is shown in Table V. The developing multiple linear regression equation as follow:

$$
M_{u-R T}=a+b_{1} f_{c u}+b_{2} V_{f}+b_{3} C C+b_{4} T_{L}
$$

TABLE V. Multiple linear regression model parameters

\begin{tabular}{|c|c|c|c|c|c|}
\hline Parameter & Intercept & $\boldsymbol{f}_{\boldsymbol{c u}}(\boldsymbol{M P a})$ & $\boldsymbol{V}_{\boldsymbol{f}} \%$ & $\boldsymbol{C C}(\boldsymbol{m m})$ & $\boldsymbol{T}_{\boldsymbol{L}}\left({ }^{\circ} \mathbf{C}\right)$ \\
\hline Coefficient Symbol & $a$ & $b_{1}$ & $b_{2}$ & $b_{3}$ & $b_{4}$ \\
\hline Coefficient value & 5.050 & 0.026 & 0.31 & -0.057 & -0.003 \\
\hline
\end{tabular}

\section{DeVeloping ARTificial NeURAL Networks (ANNs)}

A number of factors influence the performance of the neural network, which can be described as the speed of learning and the generalization capacities of neural networks. In the following, several main factors are discussed in details. Fig. 7 depicts steps of developing in flow chart.

\section{Training Algorithm}

There are different optimization techniques to be used in the training of neural networks. They have a variety of computation and storage requirements, and no one is best suited to all locations. In the following, the outlines of the two training optimization techniques that are used for building the neural network are defined [16]:

i. Steepest Descent with Momentum.

ii. Resilient Back propagation.

\section{Pre-processing and Post-processing of Data}

Data scaling is another essential step for network training. The network can be more speedy and efficient if the input and target are scaled to fall in specific range. The training is preferred if the problem region is relatively narrow in some dimensions and elongated in others.

\section{Initializing Weight Factor}

Prior to training a neural network, initial values for the weights, between the nodes of the various layers must be set. Typically, the weight factors are initialized to small and random values by using either Random or Widrow-Hoff method. When the nodes are connected by a large weight value, the neural network might become paralyzed. This phenomenon occurs since, at the high output values corresponding to the high weight value, the derivative of the transfer function approaches zero, and accordingly the weight change approaches to zero. Thus, the training of neural networks approaches to a halt. For the present study the training of the neural network is carried out using 25 data sets divided into $70 \%$ for training, $15 \%$ for testing and $15 \%$ for validation. The data sets are presented in Table VIII. 
The structure of artificial neural networks is as a rule layered. Three functional groups can be distinguished in the artificial neural network. The set of input nodes that receives information from external sources and sends signals to the subsequent layers is called input layer. The set of output nodes that receive processed information and sends output signals is called output layer. Other layer that receive information from input layerand processes them in a hidden way to output layer is are called hidden layer. The number of hidden layers and number of nodes in hidden layers depend on the complexity of the case [17]. In general, there are two major neural network architectures the first is feed forward, and the second feed backward, as shown in Fig. 8. Back propagation and Feed-forward multilayer perceptron is used extensively in engineering applications.

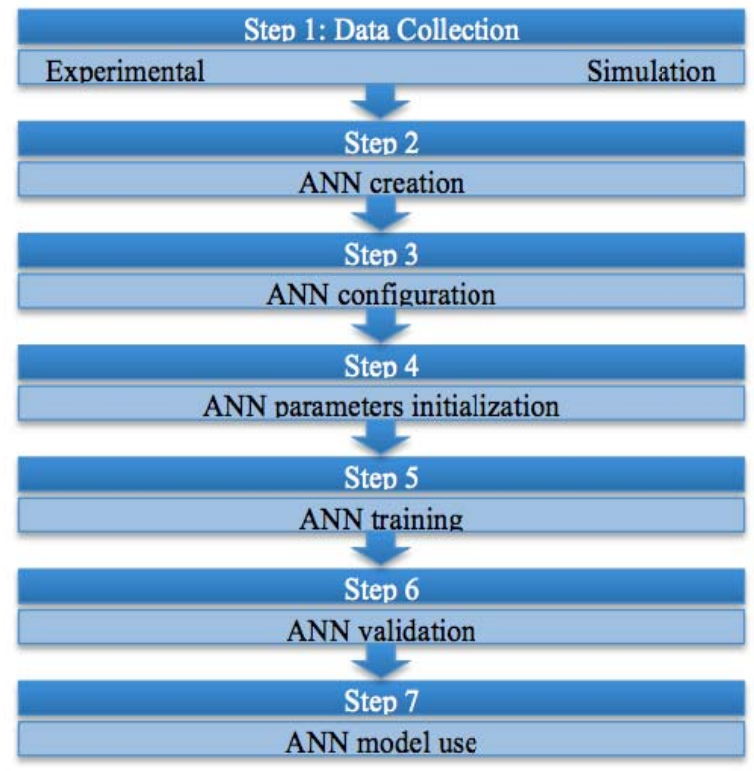

Fig. 7.Flow chart for designing ANN model

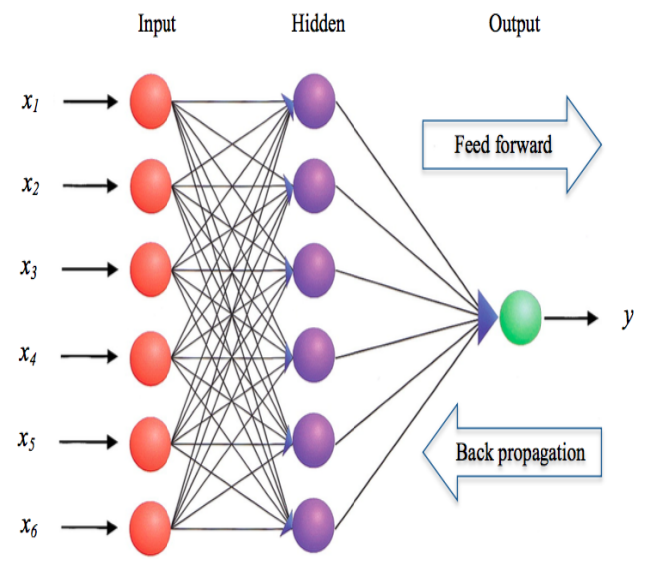

Fig. 8. Architecture of a typical ML ANN model

Choosing the appropriate number of hidden neurons and number of hidden layers are major parameters in obtaining an accurate ANN model. In addition, the best selection ofactivation function has a considerable effect on the ability of the model. The number of hidden layer and number of nodes in hidden layers are usually determined via trial and error procedures or using suggested rules. Reference [18] suggested the number of upper bound processing nodes of the hidden layers can be calculated by dividing the number of input-output pairs of the training set by the total number of input and output nodes of the network, multiplied by a scaling factor between five and ten. Larger scaling factors are used for relatively noisy data. Tables VI to VIII presented the variables data.

TABLE VI. LIST OF DEPENDENT AND INDEPENDENT VARIABLES

\begin{tabular}{|l|c|}
\hline \multicolumn{1}{|c|}{ Variable Definition } & Symbol \\
\hline Cube compressive strength (MPa) & $f_{c u}$ \\
\hline Volume fraction of micro steel fibers \% & $V_{f}$ \\
\hline Concrete cover CC (mm) & $C C$ \\
\hline Burning temperature level ${ }^{\circ} \mathrm{C}$ & $T_{L}$ \\
\hline Experimental moment carrying capacity & $M_{u-t e s t}$ \\
\hline Predicted moment carrying capacity by ANN-MLP method & $M_{u-A N N}$ \\
\hline Predicted moment carrying capacity by ML regression method & $M_{u-R T}$ \\
\hline
\end{tabular}

TABLE VII. CORRELATION MATRIX OF MODELS VARIABLES

\begin{tabular}{|c|c|c|c|c|c|}
\hline Correlation & $\boldsymbol{f}_{\boldsymbol{c u}}$ & $\boldsymbol{V}_{\boldsymbol{f}}$ & $\boldsymbol{C C}$ & $\boldsymbol{T}_{\boldsymbol{L}}$ & $\boldsymbol{M}_{\boldsymbol{u} \text {-test }}$ \\
\hline $\boldsymbol{f}_{\boldsymbol{c u}}$ & 1 & & & & \\
\hline $\boldsymbol{V}_{\boldsymbol{f}}$ & 0.714 & 1 & & & \\
\hline $\boldsymbol{C C}$ & 0.259 & 0 & 1 & & \\
\hline $\boldsymbol{T}_{\boldsymbol{L}}$ & -0.338 & 0 & 0 & 1 & \\
\hline $\boldsymbol{M}_{\boldsymbol{u} \text {-test }}$ & 0.868 & 0.709 & -0.131 & -0.526 & 1 \\
\hline
\end{tabular}


TABLE VIII. DEPENDENT AND INDEPENDENT VARIABLES RANGES

\begin{tabular}{|c|c|c|c|}
\hline \multirow{2}{*}{$\begin{array}{c}\text { Variable } \\
\text { Symbol }\end{array}$} & \multirow{2}{*}{ Unit } & \multicolumn{2}{|c|}{ Range } \\
\cline { 3 - 4 } & & Minimum & Maximum \\
\hline $\boldsymbol{f}_{\boldsymbol{c u}}$ & $\mathrm{MPa}$ & 73.3 & 151.1 \\
\hline $\boldsymbol{V}_{\boldsymbol{f}}$ & $\%$ & 0.0 & 2.0 \\
\hline $\boldsymbol{C C}$ & $\mathrm{mm}$ & 15 & 30 \\
\hline $\boldsymbol{T}_{\boldsymbol{L}}$ & ${ }^{\circ} \mathrm{C}$ & 25 & 400 \\
\hline $\boldsymbol{M}_{\boldsymbol{u} \text {-test }}$ & $\mathrm{kN} . \mathrm{m}$ & 4.41 & 9.03 \\
\hline
\end{tabular}

\section{Xi. DeVelopment Stages of Artificial Neural Network Model and Optimization}

In this study, the application of artificial neural networks model (ANN) developed to predict the ultimate moment capacity of RPC and NSC reinforced beams exposed to fire flame is investigated. An ANN model is built, trained, validated and tested using 25 data sets. The data used in the ANN model consists of 4 input parameters, which are the compressive strength of the concrete $\left(f_{c u}\right)$, volume fraction of micro steel fibers \% $\left(V_{f}\right)$, concrete cover $(\mathrm{CC})$ and burning temperature level $\left(T_{L}\right)$. The method of trial and error was carried out to define the configuration of ANN. In present study the network is trained with one hidden layer of 3 neurons. The network schematic is shown in Fig. 9. These parameters used in ANN model to predict the ultimate moment capacity $\left(M_{u}\right)$ of RPC and NSC reinforced beams with high degree of accuracy within the range of input parameters considered. The relative importance for the input parameters is shown in Fig. 10 and the major controlling parameter is the compressive strength (55.2\%).The moment capacities predicted by ANN are in line with the results provided by the ultimate moment capacity equation. These results are important as ANN model alleviates the problem of computational complexity in determining $\left(M_{u}\right)$. The ANN architecture information, the parameters estimated weights and the values database used in artificial neural network model are presented in Table IX.

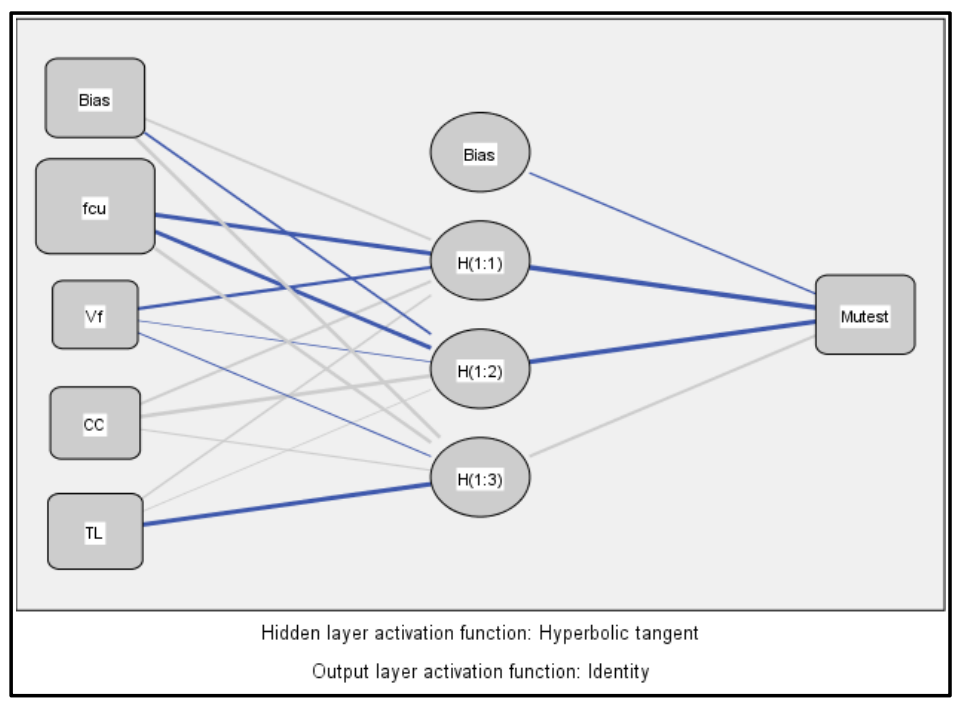

Fig. 9.Architecture Schematic of the ANN for Prediction of Ultimate moment Capacity 


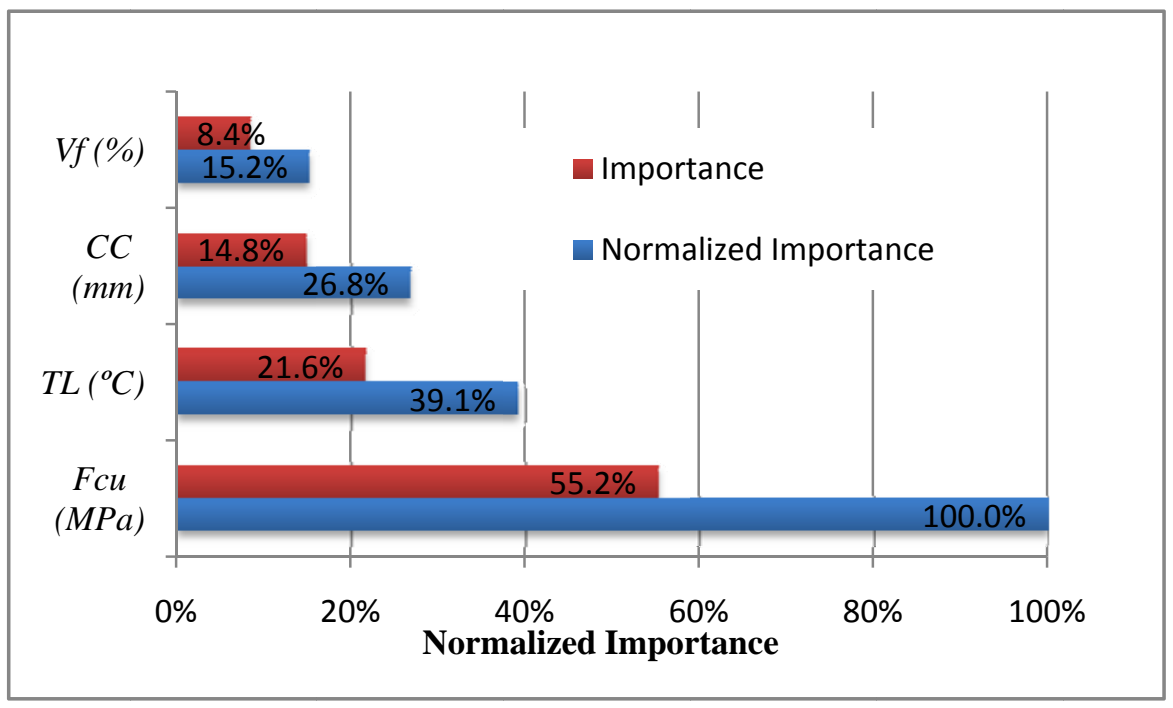

Fig. 10. The independent variables importance

TABLE IX. THE VALUES OF DATABASE USED IN ARTIFICIAL NEURAL NETWORK MODEL

\begin{tabular}{|c|c|c|c|c|c|c|}
\hline Data Type & No. & $\begin{array}{c}\boldsymbol{f}_{c u} \\
(\boldsymbol{M P a})\end{array}$ & $\begin{array}{l}V_{f} \\
(\%)\end{array}$ & $\begin{array}{c}C C \\
(\boldsymbol{m m})\end{array}$ & $\begin{array}{c}\boldsymbol{T}_{\boldsymbol{L}} \\
\left({ }^{\circ} \boldsymbol{C}\right)\end{array}$ & $\begin{array}{l}M_{u-t e s t} \\
(k N . m)\end{array}$ \\
\hline \multirow{25}{*}{ 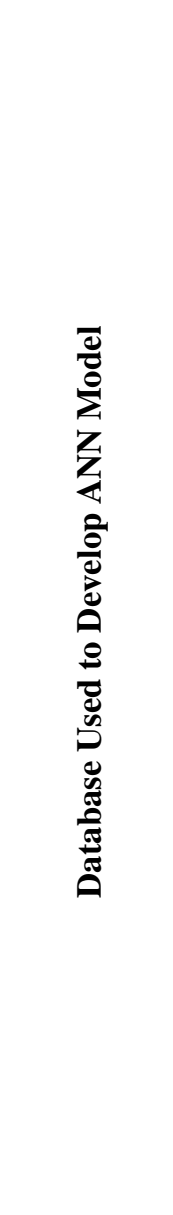 } & 1 & 133.2 & 1 & 15 & 25 & 7.50 \\
\hline & 2 & 138.4 & 1 & 15 & 150 & 7.97 \\
\hline & 3 & 119.4 & 1 & 15 & 200 & 7.10 \\
\hline & 4 & 109.7 & 1 & 15 & 300 & 6.29 \\
\hline & 5 & 101.3 & 1 & 15 & 400 & 5.45 \\
\hline & 6 & 145.3 & 2 & 15 & 25 & 8.37 \\
\hline & 7 & 151.1 & 2 & 15 & 150 & 9.03 \\
\hline & 8 & 125.4 & 2 & 15 & 200 & 7.80 \\
\hline & 9 & 119.6 & 2 & 15 & 300 & 6.95 \\
\hline & 10 & 111.2 & 2 & 15 & 400 & 6.17 \\
\hline & 11 & 122.1 & 0 & 30 & 25 & 5.99 \\
\hline & 12 & 126.9 & 0 & 30 & 150 & 6.27 \\
\hline & 13 & 102.2 & 0 & 30 & 200 & 5.42 \\
\hline & 14 & 91.9 & 0 & 30 & 300 & 4.88 \\
\hline & 15 & 73.3 & 0 & 30 & 400 & 4.41 \\
\hline & 16 & 49.2 & 0 & 15 & 25 & 5.49 \\
\hline & 17 & 44.5 & 0 & 15 & 150 & 4.80 \\
\hline & 18 & 40.7 & 0 & 15 & 200 & 4.64 \\
\hline & 19 & 39.5 & 0 & 15 & 300 & 4.38 \\
\hline & 20 & 39.1 & 0 & 15 & 400 & 4.31 \\
\hline & 21 & 145.3 & 2 & 30 & 25 & 7.47 \\
\hline & 22 & 151.1 & 2 & 30 & 150 & 7.89 \\
\hline & 23 & 125.4 & 2 & 30 & 200 & 6.81 \\
\hline & 24 & 119.6 & 2 & 30 & 300 & 6.20 \\
\hline & 25 & 111.2 & 2 & 30 & 400 & 5.21 \\
\hline
\end{tabular}




\section{XiI. Artificial neural Network Model Performance}

The performance of ANN was evaluated by conducting four statistical analyses. The performance of the inference system was measured using Root Mean Square Error (RMSE), Mean Absolute Error (MAE), Absolute average deviation (AAD)\% and the coefficient of determination $\left(\mathrm{R}^{2}\right)$. The model that minimized the error values and percentage (RMSE, MAE and $\mathrm{AAD} \%$ ) and maximized $\left(\mathrm{R}^{2}\right)$ is selected as the optimum network. These statistical parameters are used to compare the performance of the various methods (ANN and RT) as follows:

- RMSE Root Mean Square Erroris given in equation(3).The lowest RMSE coefficient is recommended.

* MAE the Mean Absolute Error, using equation (4).

* AAD\% Absolute Average Deviation is calculated to learn the accuracy of the models, using equation(5).

* $\mathrm{R}^{2}$ the coefficient of determination. The better model that $\mathrm{R}^{2}$ achieves a maximum of less than 1 , using equation (6).

$$
\begin{aligned}
& R M S E=\sqrt{\frac{1}{n}} \sum_{i=1}^{n}\left(x_{i}-y_{i}\right)^{2} \\
& M A E=\frac{1}{n} \sum_{i=1}^{n}\left|\left(x_{i}-y_{i}\right)\right| \\
& A A D \%=\left(\frac{1}{n} \sum_{i=1}^{n}\left|\left(\frac{x_{i}-y_{i}}{y_{i}}\right)\right|\right) * 100 \ldots \ldots . \\
& R^{2}=\left(1-\frac{\sum_{i=1}^{n}\left(x_{i}-y_{i}\right)^{2}}{\sum_{i=1}^{n}\left(y_{i}-y_{i A V}\right)^{2}}\right) \text {. }
\end{aligned}
$$

Where:

$x_{i}$ : Predicate data.

$y_{i}$ : Actual (Measured) value.

$y_{i \mathrm{AV}}$ : Actual average of actual values.

$n:$ The number of data.

\section{COMPARISON OF REgRESSION TECHNiQues (RT) WITH ARTIFICIAL NEURAL NETWORKS (ANN)}

Comparison results of the ANN and RT models with experimental results and evaluated by using statistical measures. Table X and XIpresent the comparison values of the ANN and RT modelswith the experimental results and the comparison results of the four statistical analyses respectively.Comparison results of ANN and RT models with experimental results are shown in Fig. 11 to 13 shows the comparison between the prediction of the ultimate moment capacity of the training and testing data with respect to the observed results. It is clear that the performance of the ANN is better than RT model.Fig. 11 and 12 show the models performance, it can be seen that ANN model results has exhibited better predictive performance and are closer to the observed results, and the moment capacity predicted by ANN are in line with results provided by experimental test.Fig. 13illustrate the ANN and RT models prediction residuals error. It can be seen that the RT errors are more scattered from the observed results, while the ANN errors are distributed close to zero axis. To show the superiority of proposed models, the RMSE, MAE, AAD $\%$ and $\mathrm{R}^{2}$ values for ANN and RT models are presented in Table XI. The comparison of the results indicate that the ANN model has a high value of $R^{2}(0.9666)$ and a lower value of RMSE, MAE and AAD\% (0.2337, 0.1572 and 2.2990) respectively, so that its performance is more accurate from RT model. 
TABLE X. The comparison values of the ANN and RT models with the experimental results

\begin{tabular}{|c|c|c|c|c|c|c|}
\hline \multirow{2}{*}{ Data Type } & \multirow{2}{*}{ No. } & \multicolumn{3}{|c|}{ Ultimate Moment Capacity $M_{u}(k N . m)$} & \multirow{2}{*}{ ANN-ERR } & \multirow{2}{*}{ RT-ERR } \\
\hline & & Test & ANN & RT & & \\
\hline \multirow{25}{*}{ 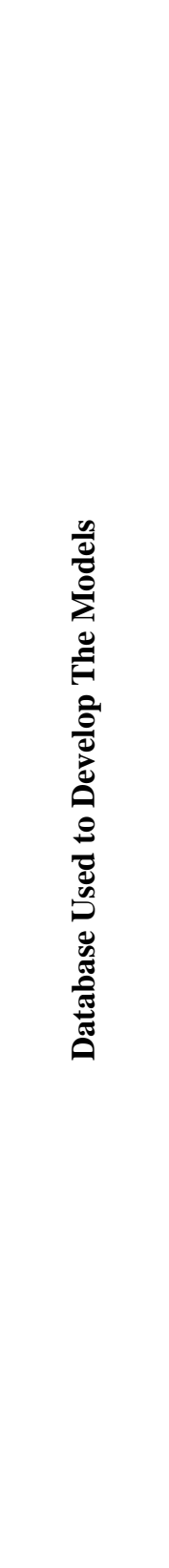 } & 1 & 7.50 & 7.95 & 7.89 & -0.45 & -0.39 \\
\hline & 2 & 7.97 & 7.81 & 7.65 & 0.16 & 0.32 \\
\hline & 3 & 7.10 & 7.11 & 7.01 & -0.01 & 0.09 \\
\hline & 4 & 6.29 & 6.33 & 6.46 & -0.04 & -0.17 \\
\hline & 5 & 5.45 & 5.63 & 5.94 & -0.18 & -0.49 \\
\hline & 6 & 8.37 & 8.34 & 8.52 & 0.03 & -0.15 \\
\hline & 7 & 9.03 & 8.24 & 8.29 & 0.79 & 0.74 \\
\hline & 8 & 7.80 & 7.62 & 7.48 & 0.18 & 0.32 \\
\hline & 9 & 6.95 & 7.03 & 7.02 & -0.08 & -0.07 \\
\hline & 10 & 6.17 & 6.32 & 6.51 & -0.15 & -0.34 \\
\hline & 11 & 5.99 & 6.21 & 6.44 & -0.22 & -0.45 \\
\hline & 12 & 6.27 & 6.10 & 6.19 & 0.17 & 0.08 \\
\hline & 13 & 5.42 & 5.43 & 5.40 & -0.01 & 0.02 \\
\hline & 14 & 4.88 & 4.94 & 4.83 & -0.06 & 0.05 \\
\hline & 15 & 4.41 & 4.39 & 4.05 & 0.02 & 0.36 \\
\hline & 16 & 5.49 & 5.38 & 5.40 & 0.11 & 0.09 \\
\hline & 17 & 4.80 & 4.85 & 4.90 & -0.05 & -0.10 \\
\hline & 18 & 4.64 & 4.63 & 4.65 & 0.01 & -0.01 \\
\hline & 19 & 4.38 & 4.41 & 4.32 & -0.03 & 0.06 \\
\hline & 20 & 4.31 & 4.29 & 4.01 & 0.02 & 0.30 \\
\hline & 21 & 7.47 & 7.67 & 7.66 & -0.20 & -0.19 \\
\hline & 22 & 7.89 & 7.57 & 7.44 & 0.32 & 0.45 \\
\hline & 23 & 6.81 & 6.53 & 6.62 & 0.28 & 0.19 \\
\hline & 24 & 6.20 & 5.89 & 6.17 & 0.31 & 0.03 \\
\hline & 25 & 5.21 & 5.16 & 5.65 & 0.05 & -0.44 \\
\hline
\end{tabular}

TABLE XI. The comparison results of the four statistical analyses with ANN and RT models

\begin{tabular}{|c|c|c|c|c|}
\hline \multirow{2}{*}{ Model Type } & \multicolumn{4}{|c|}{ Statistical Analysis } \\
\cline { 2 - 5 } & RMSE & MAE & AAD\% & $\mathbf{R}^{\mathbf{2}}$ \\
\hline ANN & 0.2337 & 0.1572 & 2.2990 & 0.9666 \\
\hline RT & 0.2998 & 0.2360 & 3.7406 & 0.9468 \\
\hline
\end{tabular}




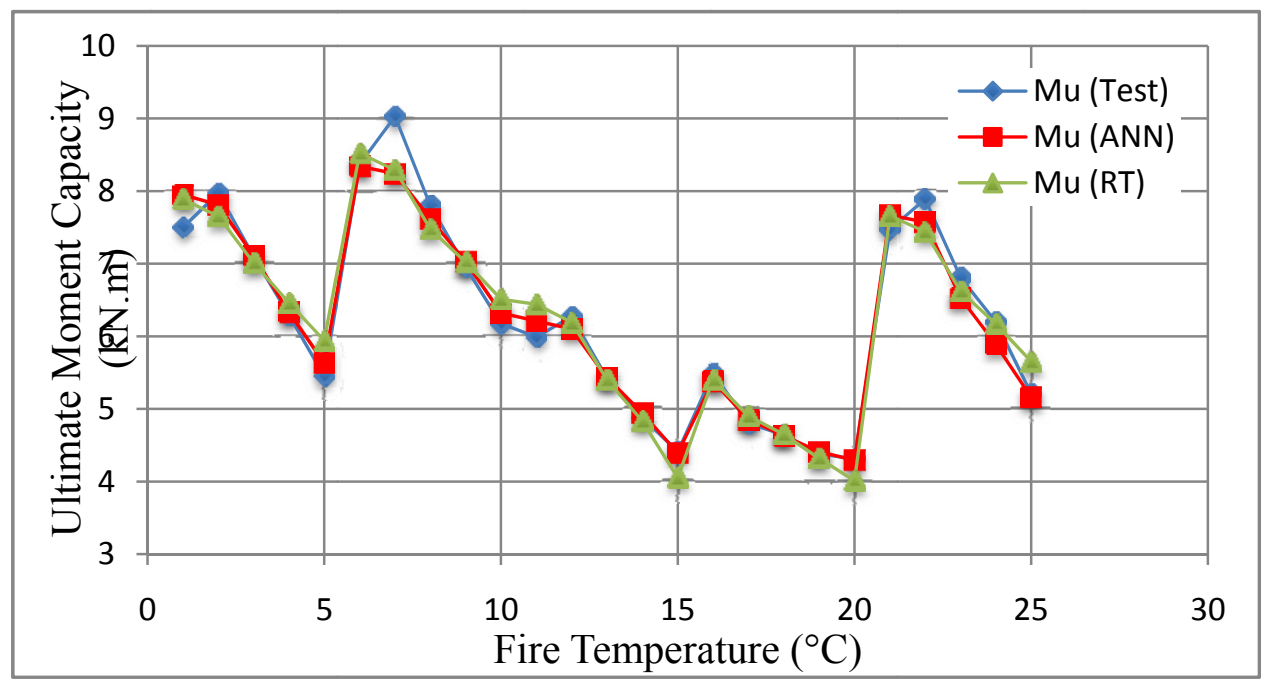

Fig. 11. The comparison results of ANN and RT models with experimental results

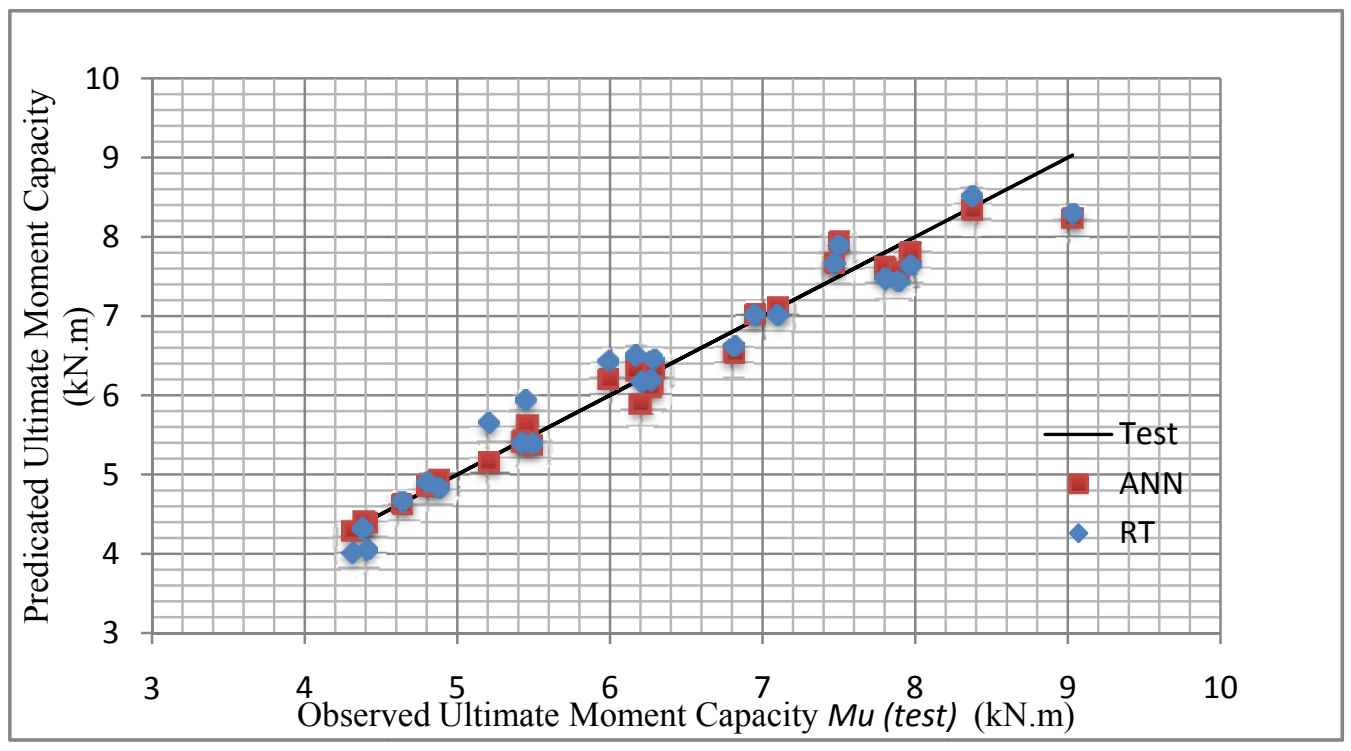

Fig. 12. The comparison of observed values with predicted values obtained from ANN and RT

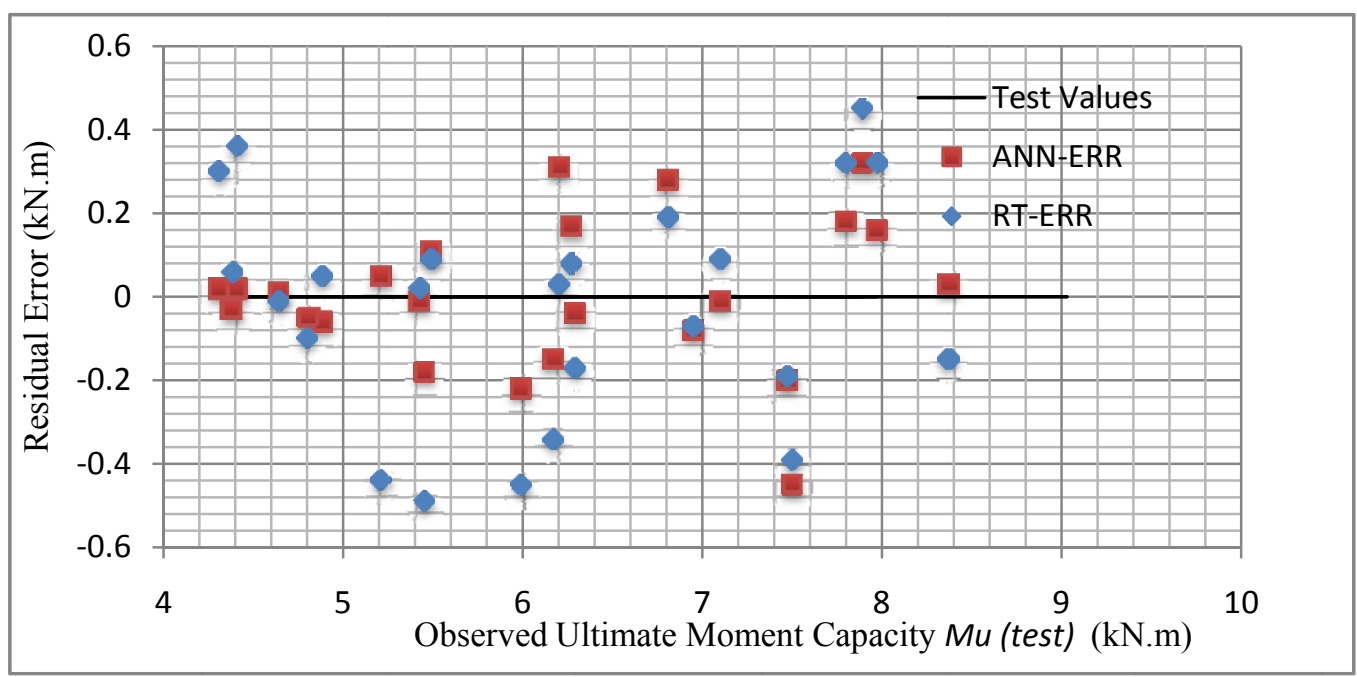

Fig. 13. The comparison of residual error values of the ANN and RT models with the predicted Values of Ultimate moment capacity $M_{u(t e s t)}$ 


\section{CONCLUSION}

Based on the experimental results presented in this research, the following conclusions are obtained from this study:

1. For the studied temperature range in this study, RPC samples had a higher strength loss than NSC samples in the temperature range between $200-400^{\circ} \mathrm{C}$.

2. In all tested beams the volume fraction $V_{f}$ used in the mixture has insignificant impact on the cracking load of RPC beams, but has a significant impact on the rate of crack propagation by reducing it through improving the tensile strength of concrete, and increases the values of the ultimate loads.

3. Two stages of cracks developed in RPC beams only after exposure to fire flame. The first stage was thermal cracks, which exhibited in honeycomb form on all surfaces; the second stage is flexural cracks, which created at tension face of the middle third span of the beam due to bending from the applied load. The cracks increase in amount and decease in width as the steel fibers ratio $V_{f}$ increases.

4. Results showed that the decreasing the concrete cover $\mathrm{CC}$ from 30 to $15 \mathrm{~mm}$ for the same volume fraction $2.0 \%$, showed a slightly increase in the values of the first crack load $P_{c r}$ and ultimate moment capacity $M_{u}$ for the RPC beam specimens at room temperature.

5. Artificial Neural Network Multi Layers Perceptron (ANN-MLP) and Multi Linear Regression technique (RT) models were developed to predict the ultimate moment capacity, results showed that the ANN model with the Multi Layers Perceptron (MLP) provided a better prediction of ultimate moment capacity than the RT model.

6. The successful performance of ANN has established the favorable potential to simulate of the complex flexural behavior of RPC beams.

\section{REFERENCES}

[1] Richard, P. and Cheyrezy, M.H., "Reactive powder concretes with high ductility and 200-800 MPa compressive strength". ACI SP; 144: 507-518, 1994.

[2] Richard, P. and Cheyrezy, M., "Composition of Reactive Powder Concretes", Cement and Concrete Research 25(7): 1501-1511, 1995.

[3] YazıcıHalit, YardımcıMert Y, YigiterHuseyin., "Mechanical properties of reactive powder concrete containing high volumes of ground granulated blast furnace slag", Cem.Concr.Compos.; 32(8): 639-48, 2010.

[4] Bayard O, Plé O., "Fracture mechanics of reactive powder concrete": material modelling and experimental investigations. Eng. Fract. Mech; 70(7-8): 839-51, 2003.

[5] Liu Chin-Tsung, Huang Jong-Shin., "Fire performance of highly flowable reactive powder concrete". Constr. Build. Mater; 23(5): 2072-9, 2009.

[6] Kadhum M., " Prediction of Mechanical Properties of Reactive Powder Concrete by Using Artificial Neural Network and Regression Technique after the Exposure to Fire Flame ". Jordan Journal of Civil Engineering, Volume 9, No. 3, 2015.

[7] The Concrete Centre, "Concrete and Fire", The Royal College of Obstetricians and Gynaecologists, Regents Park, Architects: Nicholas Hare Architects LLP, Photographer: Martin CharlesPP 1-13, 2004.

[8] Portland Cement,Iraqi Specification, IQS No. 5, 1984.

[9] Aggregate from Natural Sources for Concrete and Construction,Iraqi Specification, IQS No. 45, 1984.

[10] Chemical admixture for concrete, annual book of astm standards American society for testing and Materials, ASTM C494-01, vol.0402, pp. 245-252, 2001.

[11] Standard Specification for the Use of Silica Fume as a Mineral Admixture in Hydraulic Cement Concrete, Mortar, and Grout, ASTM C 1240-05, "Vol. 04.02, PP. 1-7, 2005.

[12] Hassan, F.H. "Punching Shear Behavior of Normal and Modified Reactive Powder Concretes Slabs". Al- Mustansiriya University, Baghdad, Iraq, PhD Thesis, Department of Civil Engineering (Structures), College of Engineering, September, 188p, 2012.

[13] Hussein, A.A. "Punching Shear Strength of Reactive Powder Concrete Flat Plates". Al- Mustansiriya University, Baghdad, Iraq, M.Sc. Thesis, Department of Civil Engineering, College of Engineering, October, 124p, 2011.

[14] Standard Test Methods for Fire Tests of Building Construction and Materials, ASTM E119-02,American Society for Testing and Materials, West, Conshohocken, PA, 2002.

[15] Jerzy, H., and Krzysztof, S., "Application of Artificial Neural Network to Determine Compressive Strength Based on Non-Destructive Test", Journal of Civil Engineering and Management, Vol. XI, No.1, pp. 23-32, 2005.

[16] Artificial Neural Network Toolbox User's Guide, 2004.

[17] Lau, C., "Neural Networks: Theoretical Foundation and Analysis", New York: IEEE Press, 1992.

[18] Anderson, D. and McNeill, G., Artificial Neural Networks Technology, Rome Laboratory, NY, Rome, 1992. 